\title{
Special Contribution
}

OPEN ACCESS

\section{A Workable Framework or a Fuzzy Concept? The Regional Resilience Approach to the Evolution and Adaptability of Regional Economies}

\author{
Cheol-Joo Cho* \\ Department of Urban Studies and Planning, Cheongju University, Republic of Korea
}

\begin{abstract}
This paper aims at exploring a conceptual framework of analyzing the evolutionary processes of regional economies by reconciling the notion of regional resilience and the concepts prevailing in the disciplines of evolutionary economics and geography. The resilience framework appears to offer a promising outlet with which combination of the seemingly contradictory conceptions is made possible. It can address why some regions manage to adapt to external shocks, renew themselves, or lock out themselves, while others are more locked in decline. In addition, it can also explain how the spatial organization of economic production, distribution, and consumption is transformed over time. Then, regional economic resilience, together with its accompanying vehicle of panarchy, emerges as a workable framework of explaining regional differentiation in regional economic performance and trajectories. Despite the risk of being a fuzzy concept, the resilience conception can be properly operationalized to provide policy principles of regional economic innovation adjusted to region-specific contexts.
\end{abstract}

Keywords: Regional resilience, Equilibrium, Economic adaptability, Evolutionary economics, Panarchy, Path dependence, Lock-in

\section{INTRODUCTION}

In recent years, it becomes the norm that great uncertainty stemming from global recession, climate change, the arrival of era of peak oil, etc., hits all scales of localities and regions, challenging them to seek way out from various forms of unprecedented conundrum and complexity. Under the high instability of the economic, political, or ecological environments, the hegemonic discourse of regional economic strategies is overwhelmed by the principle of competitiveness. Ascending to the status of a key discursive construct, the competitiveness hegemony renders the ultimate objective of territorial and economic development to focus on the creation of economic advantage through superior productivity, or the attraction of

*Correspondence to : Prof. Cheol-Joo Cho

Department of Urban Studies and Planning, Cheongju University, Republic of Korea E-mail : cheoljcho@cheongju.ac.kr

World Technopolis Review

Copyright $(C$ World Technopolis Association

CC This is an open-access article distributed under the terms of the Creative Commons Attribution Non-Commercial License(http://creativecommons.org/icenses/by-nc/3.0) which permits unrestricted noncommercial use, distribution, and reproduction in any medium, provided the original work is properly cited new firms and labor (Krugman 1995; Porter 2003; Bristow 2005 , 2010; Jessop 2008). However, the dominant discourse of competitiveness, which is narrowly and asymmetrically constructed on growth and its underlying mechanisms, is necessarily insensitive to place-specific contingencies and furthermore, the disastrous consequences of the voracious growth imperatives at the heart of competitiveness.

The discourse centered on competitiveness fails to address one of the most intriguing questions in spatial economics: Why do some regions manage to adapt to external shocks, renew themselves, or lock out themselves, while others are more locked in decline? The discipline of evolutionary economic geography provides a promising approach to theorizing the different ways in which an economy, through its constituent actors and institutions responses, adjusts to changing circumstances (Hassink 2010). Taking seriously into account place-specific elements and processes to explain the broader spatial patterns of technology evolution, evolutionary economic geography addresses the processes by which the spatial organization of economic production, distribution, and consumption is transformed over time (Boschma and Martin 2007). To explain the forces and elements that lie behind the 
process with which some regional economies lose dynamism and others not, evolutionary thinking hires several key concepts such as including path dependence, lock-ins, path creation, related variety, co-evolution, sunk cost, cluster life cycles and the learning region (Hassink 2010).

On the other hand, regional resilience emerges as an alternative framework of explaining regional differentiation in economic performance and trajectories. The term is so malleable such that no consensus exist on its definition, means different things to different people and disciplines. For example, in ecological studies, resilience describes biological capacity to adapt to and thrive under adverse environmental conditions, whereas, in economics, it is defined as return to a fixed and narrowly defined equilibrium or, in the more liberal version, multiple equilibria. However, recently, in the social sciences, regional resilience has gained currency because of its association with regional adaptation, and consequently, become to share common grounds with evolutionary economics and evolutionary economic geography (Christopherson et al. 2010).

From a segment of the academia of regional economic research, it is notable, the equilibrium conception of regional resilience is highly criticized as a valid framework for exploring the factors leading to the capacity for adaptation and renewal of regional economies (Hassink 2010; Pike et al. 2010). However, it can be argued that the adaption-centered perspective of resilience can shed light more to the concepts of sustainability, localization, and diversification, avoiding the placeless interpretation that results from a focus on competitiveness alone. In other words, it has potential to convey a holistic approach to economic adjustment, involving actors, institutions, and context-specific resources.

Regional resilience, as it still is in the infancy stage, raises contentious debates over conceptual definitions, research methodology, theoretical significance, and practical utility. Reflecting the ongoing controversies, this paper aims to explore the potential contribution of the resilience framework to regional economic evolution and policies. In the next section, discussed are equilibrium-oriented concepts and metaphors of regional resilience. This is followed by an extension of regional resilience thinking to the panarchy model, an evolutionary adaptation framework of addressing the development trajectories of regional economies. Next, the evolutionary adaption perspective of resilience is tentatively operationalized to implement regional economic analysis and policy principles. Finally, conclusions and suggestions are offered.

\section{EQUILIBRIUM APPROACH TO REGIONAL RESILIENCE}

Resilience in social and economic systems emerges an area of attraction as comebacks from various unexpected disastrous shocks to the system ranging from economic recession and corporate bankruptcy to desert recharge and terrorist attacks become imminent policy concern. The meaning of resilience has been extended and explained across several fields, including ecology, psychology, economics, and disaster studies. A review of the related literature identifies two common frameworks underlying resilience thinking: one is equilibrium analysis and the other complex adaptive systems analysis (Pendall et al. 2010). This section devotes to exploring the former framework, while the latter is examined in the next section.

The equilibrium approach to regional resilience is further split into two versions. The first is related to more traditional definition of resilience, i.e. engineering resilience. It concentrates on the stability of a system near an equilibrium or steady state (Simmie and Martin 2010). Under this definition, the idea of resilience is defined as resistance to disturbance and the speed of return to the pre-existing equilibrium (Holling 1973; Pimm 1984). This echoes McGlade et al.'s (2006) notion of elasticity or the ability of a system to absorb and overcome perturbation without experiencing major structural transformation or collapse. Translated into regional economies, regional resilience, following an economic shock, implies the return of the region's pre-shock structure by returning from off the equilibrium path. Then, it is argued that a shock or disturbance shifts the regional economy off its equilibrium growth path, but the economy's self-correcting forces and adjustments, if the regional economy is resilient, bring it back into that path.

The notion of this kind of resilience as bounce-back to the pre-existing single-equilibrium bears a close affinity with the standard concept of equilibrium in neoclassical economics. In this view, a resilient region is the one that recovers its previous functions, population, economy, growth trajectory, or built form after a shock (Vale and Companella 2005). Various regional incidents such as growth or decline in population, output, unemployment, poverty, or labor-force participation can be considered at least partly equilibrium phenomena. Given that these regional occurrences attract significant interest from academics and policy makers alike, the single-equilibrium version of resilience offers somewhat meaningful metaphor for understanding regional adaptability. <Fig. $1>$ shows 
the varying degrees of resilience of a regional economy to a major shock in a highly stylized fashion, according to the deviations of bounce-back from the pre-existing equilibrium path. $<$ Fig. $1(a)>$ fits the concept of engineering resilience of regional economies.

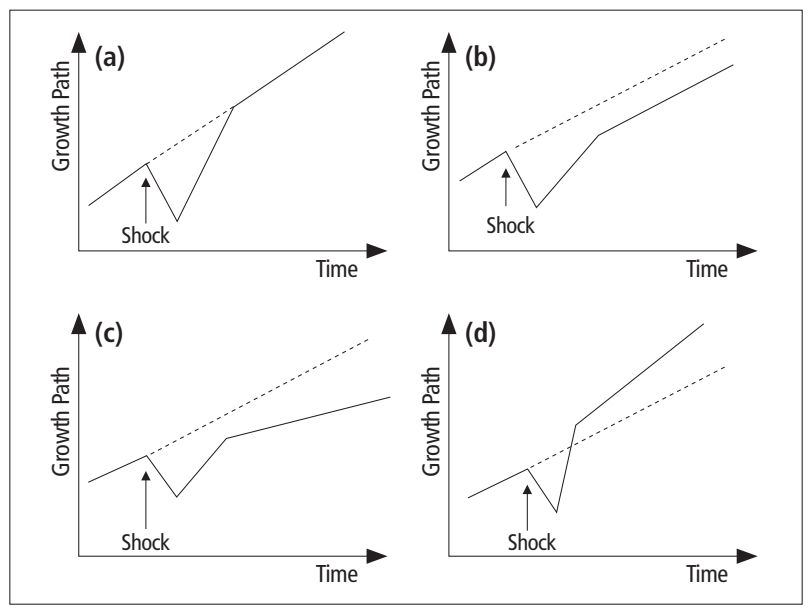

Fig. 1. Stylized responses of a regional economy to a major shock

Notes: (a) Return of region to its pre-existing steady growth path following the shock; (b) and (c) region fails to resume former steady growth path after the shock, but settles on inferior path; and (d) region recovers from shock and assumes an improved growth path.

Source: Simmie and Martin (2010)

However, despite the theoretical appeal, seeing resilience in terms of the ability to return to the previous equilibrium path is not totally supported. The notion of the pre-existing equilibrium growth path is of limited validity and furthermore. That is, the idea that, once any such path is disrupted, it is still there in theory, waiting to be rediscovered, is hardly acceptable (Christopherson et al. 2010). One obvious problem with the idea of the single-equilibrium path is its failure to reconcile the notion of bounce-back with the idea of regional economic evolution, which would more precisely represent the reality.

As the single-equilibrium version of resilience is subject to significant limits and skepticisms, the second definition of equilibrium in regional resilience, which is a more realistic idea of resilience, becomes to gain ground. It is the notion of so-called ecological resilience. This form of resilience is drawn on from the concept of multiple equilibria in which, instead of coming back to the pre-existing equilibrium path, shifting to new or no normal paths following a disturbance is presumed. The multiple-equilibria system focuses on whether disturbances or shocks cause the system to move another regime of behavior, pushing a system beyond its elasticity threshold to a new domain (Simmie and Martin 2010; Martin 2012).

This notion is based on the presumption that a system might have multiple equilibria, entailing different conditions of resilience under which disturbances flip a system from one equilibrium to another. According to this definition of resilience, if the previous growth path is broken for any reasons, there may be one or more alternative growth paths that the system may achieve through industrial restructuring and repositioning. Then, the important measure of resilience is the magnitude of disturbance that can be absorbed before the system changes in structure by the change of variables and processes that control system behaviors, that is, a measure of robustness and buffering capacity of the system to changing conditions (Berks and Folke 1998; Martin 2012). Here, systems are seen to be permeated by uncertainty and discontinuity, thereby rendering them to be complex, non-linear, multi-equilibrium, and self-organizing. <Fig. 1(b), 1(c), and $1(d)>$ illustrate various impacts of a recessionary shock on a region's growth path. Of these, <Fig. 1(b) and 1(c)> represent the cases where the impact of the recessionary shock is so destructive such that the negative aspects of economic downturn outweigh any compensating growth of new firms and jobs. On the other hand, <Fig. $1(\mathrm{~d})>$ shows that the regional economy more than rebounds from a recessionary shock at the rate above the pre-shock growth rate.

Meanwhile, the shift of concern from single equilibrium to multiple equilibria entails the exploration of three key attributes of resilience in multi-equilibrium systems, including latitude $(\mathrm{L})$, resistance $(\mathrm{R})$, and precariousness $(\mathrm{Pr})$ (Walker et al. 2004; Yamamoto 2011) ${ }^{1}$. All systems are continuously buffeted

\footnotetext{
${ }^{1}$ Resilience is the capacity of a system to absorb disturbance and reorganize while undergoing change so as to still retain essentially the same function, structure, identity, and feedbacks--in other words, stay in the same basin of attraction. A basin of attraction is a region in state space in which the system tends to remain. For systems that tend toward an equilibrium, the equilibrium state is defined as an attractor, and the basin of attraction constitutes all initial conditions that will tend toward that equilibrium state. Walker et al. (2004) define resilience in terms of latitude (L), resistance (R), and precariousness ( $\operatorname{Pr}$ ). Latitude means the maximum amount the system can be changed before losing its ability to recover, basically the width of the basin of attraction. Wide basins mean that a greater number of system states can be experienced without crossing a threshold. Resistance, which measures the ease or difficulty of changing the system, is related to the topology of the basin--deep basins of attraction (R, or more accurately, higher R to L ratios) indicate that greater forces or perturbations are required to change the current state of the system away from the attractor. Precariousness is the current trajectory of the system, and how close it currently is to a limit or threshold which, if breached, makes recovery difficult or impossible.
} 
by disturbances that tend to move the system off the attractor. Accordingly, systems move about within a particular basin of attraction, rather than tend directly toward another attractor. There may be more than one such basin of attraction for any given system, for example, two or more combinations of amounts of grass, shrubs, and livestock toward which a rangeland might move, depending on the starting point. The various basins that a system may occupy, and the boundaries that separate them, are known as a stability landscape (Beisner et al. 2003). $<$ Fig. 2(a) $>$ depicts the three components of resilience for a basin in a stability landscape of two state variables.

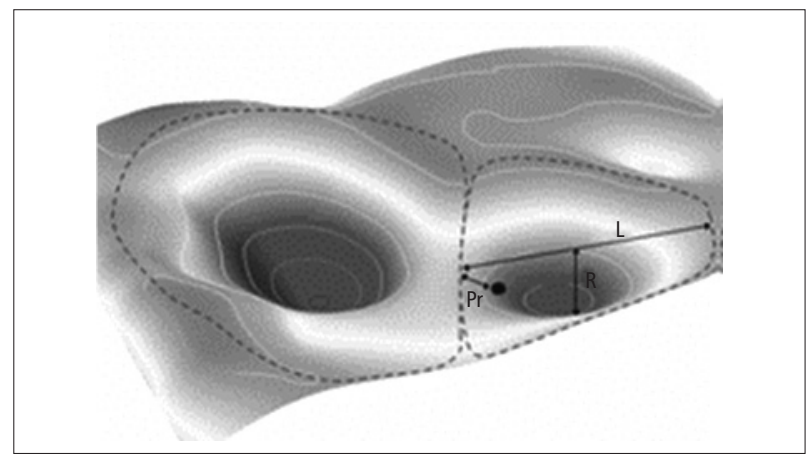

Fig. 2(a). Three-dimensional stability landscape

Notes: This stability landscape with two basins of attraction shows the current position of the system in one basin and depicts three aspects of resilience: latitude $(\mathrm{L})$, resistance $(\mathrm{R})$, and precariousness $(\operatorname{Pr})$.

Source: Walker et al. (2004)

In a sense, it can be said that institutional economics and evolutionary geography espouse the conception of putative multi-equilibrium systems, especially those that are stuck at a sub-optimal level, a phenomenon sometimes called lock-in (Pendall et al. 2010). Here, the state of lock-in results from institutional tissues, which consist of formal organizations, such as political and administrative entities at all levels, trade unions, enterprises and business support agencies, and things that pattern behavior, such as norms, rules, and laws (Hassink 2005). Lock-in is closely related to path dependence, as the former is a consequence or manifestation of the latter. Rising of one technological or political regime to hegemonic position entails the system to take shape that reflects and responds to the dominant regime, thereby developing a complex social, physical, economic, and cultural institution that makes it difficult to avoid the development path of that regime (Hassink
Both exogenous shocks and endogenous processes cause changes in the stability landscape: changes in the number of basins of attraction; changes in the positions of the basins within the state space; changes in the positions of the thresholds between basins (L); or changes in the depths of basins, which measures difficulty to move the system around within the basin $(\mathrm{R})^{2}$. Moving the system around changes its position within a basin relative to the edge (Pr), or moves it into a new basin as shown in $<$ Fig. 2(b) $>$, where, without changing the state of the system itself, the system finds itself in a new basin of attraction, owing to changes in the stability landscape.

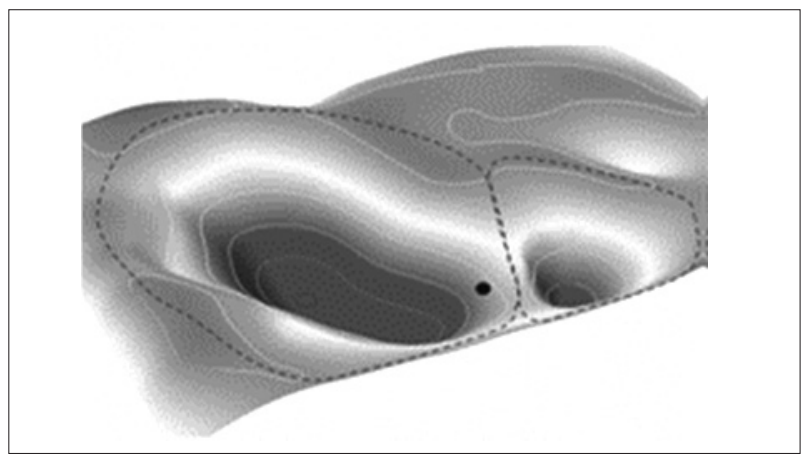

Fig. 2(b). Changes in the stability landscape

Notes: Changes in the stability landscape result in a contraction of the basin where the system was in and an expansion of the alternate basin. Without itself changing, the system changes basins.

Source: Walker et al. (2004)

2005, 2010; Pendall et al. 2010).

Without a massive or radical shock, then, path-breaking behaviors and changes with which the locked-in pathway can be shattered are not formulated. A long historical observation indicates that institutional arrangements and market peculiarities cause sub-optimal equilibria to persist for a long time. Therefore, systems that appear to be punctuated by sub-optimal outcomes or volatile changes in the medium term might be on non-equilibrium or, at best, dominated by optimal outcomes on average (Pendall et al. 2010). Many regional problems that, despite the metropolitan reformers' long struggles, still remain unresolved, such as urban sprawl, central city decline and long-term economic distress, reveal the persistence of sub-optimal equilibria. The metropolitan problems are alleged consequent of local government structures that have locked-in unchanged for a long time. Seen from the institu-

${ }^{2}$ Steep sides imply greater perturbations or management efforts are needed to change the state of the system, i.e. its position within the basin (Resistance). 
tional economics and evolutionary perspective, this means that, only through unlocking the locked-in pathway, in this case, through the restructuring of government systems of all scales, those problems would be resolved.

Under the view of multiple equilibria, regional systems are regarded to follow a process of punctuated equilibration, a succession of steady growth paths, or hysteretic movements. This notion of punctuated equilibrium certainly fits the evolution processes and behaviors of biological and ecological systems. However, it is dubious that it is still a valid model for replicating the evolutionary paths of social and economic systems. While ecological systems, if left undisturbed, may perhaps attain equilibrium or stable states, socio- economic systems are arguably different (Simmie and Martin, 2010). While the multiple equilibria model might be useful for modeling purposes, real social and economic systems are unlikely to bear much resemblance to multiple equilibria. In fact, regional economies are constructed through the intricate interplay of human actions and social relations. They collectively create capacity, including governance capacity, constantly respond to external shocks or disturbances, and determine how vulnerable a region is to events outside the control of regional agents. Then, it can be said that regions are a manifestation of social constructs and are going through a constant process of transition (Christopherson et al. 2010).

In consequence, seen from the evolutionary approach to understanding regions, the idea of multiple equilibria is weak as a medium of measuring regional resilience. Certainly, regional economies exhibit some tendencies toward stabilizing forms and self-organizing properties. But, the evolutionary perspective, the terms of stability, ex-ante equilibrium state, and self-organization do not have the same connotations as resilience (Martin and Sunley 2006, 2007; Simmie and Martin 2010). Then, for a better understanding of socio-economic systems resilience, we need to look for alternative thinking with which the concept of evolutionary adjustment and adaptation can shatter the strong connotation of punctuated change tainted by multiple equilibria. The framework of complex adaptive dynamics, which requires no assumptions about equilibrium, offers a promising outlet for the discourse of systems resilience. The adaption-centered evolutionary view recognizes regional resilience as a process rather than a descriptor, shifting inquiry from questions about how much a regional economy is resilient to how it adapts over time to various kinds of disturbance. Regional resilience in the evolutionary adaptive cycles is explored in the next section.

\section{ADAPTIVE EVOLUTIONARY CONCEPTION OF REGIONAL RESILIENCE}

Regarding regional economic growth and decline, several ideas have been suggested with which regional resilience can be viewed from the adaptation and evolutionary perspective. Simmie and Martin (2010) distinguish four conceptual frameworks for constructing an evolutionary account of regional economic resilience and adaption: (i) generalized Darwinism; (ii) path-dependence theory; (iii) complexity theory; and (iv) panarchy. First, generalized Darwinism emphasizes variety in shaping regional economic resilience, which is expressed in terms of sectoral variety and variation in firm behavior, novelty, and selection. It employs three mechanisms to explain how entities change to better adapt to environmental shifts (Toulmin 1981). One is internal responses to perception of circumstances; a second is homeostatic response, the automatic compliance to specific rules in relation to target behaviors; and a third is developmental response, the cumulative unfolding of new behavior patterns, such as innovation, within a specific set of constraints.

Second, path-dependence theory focuses on lock-in, the process whereby a regional economy becomes locked into a particular trajectory of economic development through the operation of self-reinforcing localized increasing returns, or the emergence of new paths enabled by the pre-existing resources, competences, skills, and experiences inherited from previous local paths. Then, two interpretations of lock-in, i.e. positive or negative, are possible (Lambooy and Boschma 2001). The positive attribute of lock-in applies to the case that a regional economy maintains its locked-in development path under external shocks. In contrast, a negative lock-in occurs when a region holds back the adaptation of its economy to a shock. In the former, the path-dependent lock-in enhances the regional economy's resilience, while the latter case undermines regional resilience.

Third, complexity theory highlights self-organizing macro-scale structures and dynamics emerging out of micro-scale behaviors and interactions of system components. Compared with general Darwinism and path-dependence theory, this theory places disparate emphasis on evolutionary dynamics of complex adaptive systems. Complex adaptive systems are characterized by some distinctive attributes: distribution of functions and relationships across system components at a whole variety of scales; non-linear, path-dependent dynamics of complex feedbacks and self-reinforcing interactions among 
system components; and emergence and self-organization (Martin and Sunley 2007; Simmie and Martin 2010). These characteristic features imply that a conflicting tendency is inherent in the complex adaptive system. Specifically, a complex adaptive system tends to move toward increasing connectedness and order among systems components. However, the increasing connectedness and order reduce the system's adaptability to changes in environmental conditions, i.e. systems resilience. Thus, it can be claimed that complex adaptive systems are exposed to a trade-off or conflict between connectedness and resilience. This point points out that a more internally connected system is less adaptive and resilient to external shocks and disturbances.

Finally, panarchy, which constitutes the prime focus of discussion of this section, is a conceptual framework to combine the notion of adaptive cycles with the framework of complex adaptive systems. The panarchy model has been developed to account for the dual and seemingly contradictory attributes of all complex systems, i.e. stability and change, and thereby to explain how economic growth and human development depend on ecosystems and institutions and how they interact and change over time. It is an integrative framework, bringing together ecological, economic, and social models of change and stability, to account for the complex interactions among both these different areas and different scale levels (The Sustainable Project [online]).

In fact, the development of panarchy is strongly rooted in the ecological approach to resilience (Holling and Gunderson 2002; Folke 2006; Nelson et al. 2007). Yet, its theoretical assumptions and emphasis resonate with the already existing interests and familiar notions prevailing in the disciplines of regional economic analysis and development (Yamamoto 2011). The potential of the panarchy model to analyze complex dynamics of social and economic systems is demonstrated by the increase in the number of relevant literature paying attention to it.

Panarchy posits that the fullest expression of systems resilience emerges from four-phase adaptive cycles of continuous adjustment to internal and external forces. Each adaptive cycle (system) operates on its own $<$ Fig. $3>$ cyclical evolutionary dynamics, represented by sequential four phases: (i) growth/ exploitation (r); (ii) conservation/consolidation (K); (iii) collapse/release, often triggered by a significant disturbance $(\boldsymbol{\Omega})$, and (iv) reorganization ( $\alpha$ ) (Holling and Gunderson 2002; Yamamoto 2011). Each phase on the adaptive cycles is characterized by varying levels of three dimensions: (i) potential (accumulated resources to the system); (ii) connectedness (internal links among system actors and variables); and (iii) resilience (system vulnerability to shocks and disturbances) (Holling and Gunderson 2002; Pendall et al. 2010; Simmie and Martin 2010; Yamamoto 2011). From the standpoint of regional economies, the potential and connectedness dimensions can be operationalized as follows (Simmie and Martin 2010):

- Potential, which means the accumulated resources, includes the competences of individual firms, the skills of local workers, institutional forms and arrangements, physical and soft infrastructures, such as business and work cultures, and the like. These depend on previous forms and structures of economic and social development in the region.

- Internal connectedness relates to patterns of traded and untraded interdependencies among local firms, including supply of inputs, horizontal inter-firm divisions of labor in production, local networks of trust, knowledge spillover, formal and informal business associations, inter-firm labor mobility, and so on. These would be shaped by previous economic developments in the region. Creative and flexible responses depend on the innovative capacity of local firms, entrepreneurial capabilities and new firm formation, institutional innovation, access to investment and venture capital, and willingness of workers to reskill.

By the way, as mentioned earlier, connectedness and resilience tend to move in opposite directions with each other, thereby establishing a trade-off or conflict relationship between them. $<$ Fig. $3>$ shows diagrammatic presentation of a representative four-phase adaptive cycle as applied to a regional economy, together with varying levels of the potential, connectedness, and resilience dimensions at each phase.

On the other hands, the panarchy model places great emphasis on the interconnectedness across different scales--both time and space--between the larger and smaller and between the faster and slower. The panarchy model is structured in a series of nested adapted cycles operating and interacting continually at different scales and periodicities. The larger, slower cycles set the conditions for the smaller, faster cycles to operate. Conversely, the smaller, faster cycles can also have an impact on the larger, slower cycles. In panarchy, cross-scale linkages are established through two mechanisms, i.e. a revolt function and a memory function. A revolt function occurs 


\section{Special Contribution}

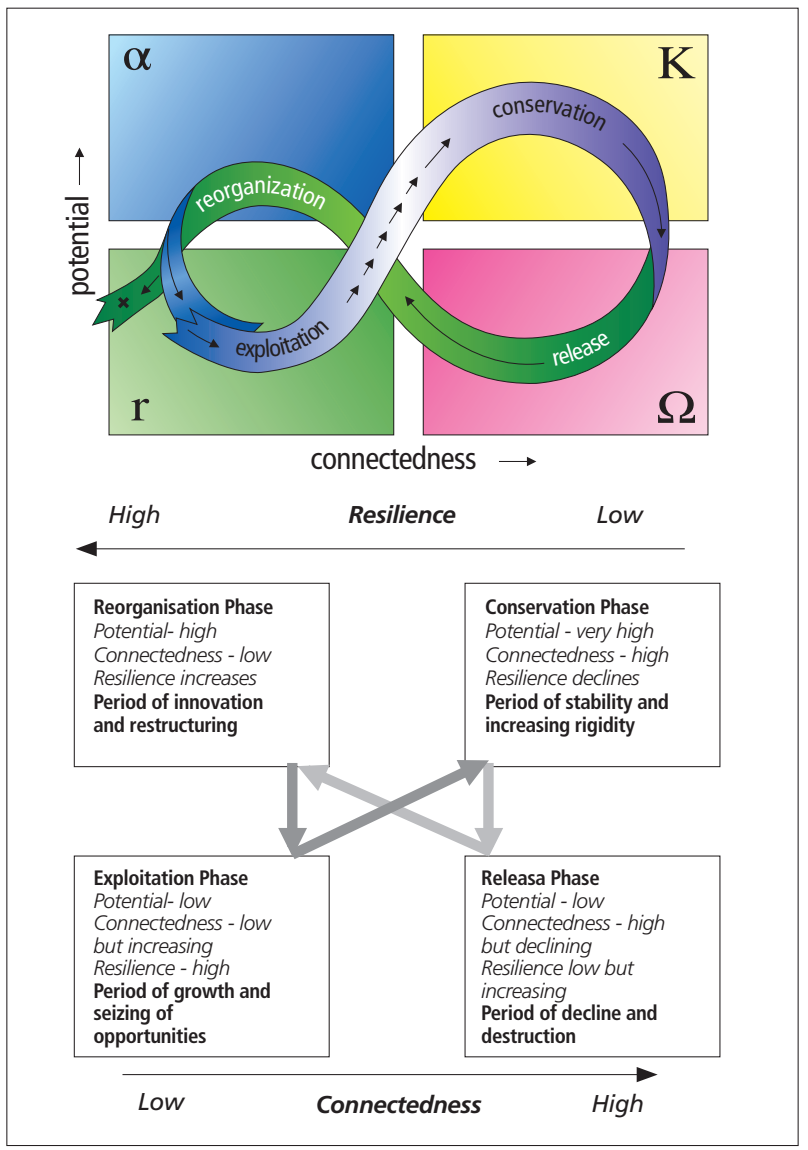

Fig. 3. A four-phase adaptive cycle model of regional economic resilience Sources: Holling and Gunderson (2002) and Simmie and Martin (2010)

when fast, small events overwhelm large, slow ones, as when, for example, a surge in community mortgage foreclosures disrupts the broader regional economy. If a regional system lacks resilience, the foreclosure revolt may propel the region into a downward spiral of indefinite vacancies, widespread abandonment, and spreading blight (Swanstrom et al. 2009). Another example of revolt occurs when a small fire in a forest spreads to the crowns of trees, then to another patch, and eventually the entire forest. In contrast, a memory function occurs when the potential accumulated and stored in the larger, slow levels influences the reorganization. Long-term, large area processes, such as a broadly diversified and strong economy, can shape the adaptive cycles and economic outcomes of smaller systems. Similarly, after a forest fire, the processes and resources accumulated at a larger scale reduce the leakage of nutrients, and options for renewal are drawn from the seed bank, physical structures, and surrounding species that form a biotic legacy.

Indeed, the notion of cross-scale linkages, which is one of the core elements of the panarchy model, is strongly consistent with new emerging inquiries posed from evolutionary geography, new regionalism, and institutional economics. The new emerging inquiries commonly highlight the significance of scale specificity, inter-scale interactions, and new politics of scale (Brenner 2001; Swyngedouw 2004; Jessop 2005; McLeod and Jones 2007; Hassink 2010; Simmie and Martin 2010). Thus, it can be argued that the notion of cross-scale connectedness inherent in panarchy echoes the conception of the new politics of scale, whereby regarding the evolutionary change of a system as a result of place-specific political responses to the forms of cross-scale socio-spatial and economic processes.

$<$ Fig. $4>$ visualizes the full-sized four-phase panarchy model with nested adaptive cycles and cross-scale interactions. In the model, each cycle could represent a local, a provincial, or a county economy. Potential (y-axis) indicates the wealth of the system, and is expected to increase in conjunction with increased system efficiency, but also accompanies increasing Connectedness (x-axis) of system components. The model also includes Resilience as the third dimension, depth of the systems space (z-axis), and hypothesizes that regional resilience is relatively higher in the growth/exploitation (r) and reorganization $(\boldsymbol{\alpha})$ phases, while lower in the conservation/ consolidation $(\mathrm{K})$ and collapse/release $(\boldsymbol{\Omega})$ phases. Thus, the evolutionary adaptive cycle model does not say about whether

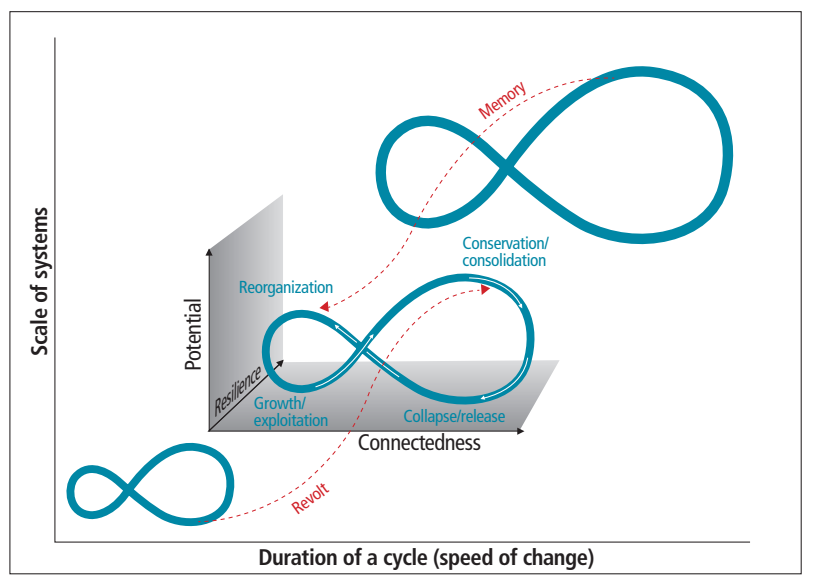

Fig. 4. A nested panarchy model with three nested adaptive cycles

Notes: The y-axis indicates potential, the wealth of the system, while the $\mathrm{x}$-axis represents internal connectedness. The third dimension (Z-axis) represents the depth of the systems space, resilience.

Sources: Holling and Gunderson (2002) and Ymamoto (2011) 
the system is resilient, or not. Rather, it informs that levels of resilience continually vary as the system adapts and changes, positing the highest levels of resilience when the system exhibits its greatest flux and flexibility (Pendall et al. 2010).

So far in this section, the basic structures and crucial attributes of the alternative evolutionary adaptive models has been examined. Of the alternative perspectives, the panarchy model appears highly suggestive with respect to regional economic analysis and policy. It offers a possible outlet within which some conceivable policies compatible with the evolutionary adaptive mechanisms of regional economies could be suggested. The panarchy model, if supplemented with burgeoning inquiries emerging from institutional economics and evolutionary geography, could lead to a better understanding of regional economic conditions and relevant policy principles. In the next section, this possibility is attempted.

\section{POTENTIAL OF THE PANARCHY MODEL FOR REGIONAL POLICY}

As an approach to understanding regional resilience, the panarchy model combines two matching notions, i.e. complex systems and adaptive cycles. This hybridization nature of panarchy means that an evolutionary perspective, which accords much attention to the processes and mechanisms by which the real economy evolves through real time, permeates into its conception. Then, it can be claimed that panarchy fits the basic concepts on which evolutionary economics and evolutionary economic geography are based for developing their theoretical foundations (Boschma and Martin 2007). First, under the panarchy framework, systems are assumed to self-transform themselves not through a dynamical, irreversible process, in which stationary states or equilibrium movements continually mutates, but through a kind of dynamical process, by which systems emerge, converge, diverge, or reach other regular patterns and trajectories that are rooted in real historical time. Second, the panarchy framework certainly takes the view of a decisive role of novelty as the ultimate source of systems self-transformation and economic evolu- tion. The perspective of novelty-determinism here recognizes the creative capacity of economic agents, e.g. individuals and firms, and the creative functions of markets, as a crucial source of self-transformation of economies. This means that innovation and knowledge occupy central importance in the panarchy model as it applies to analyzing the processes of transformation of regional economic systems.

In fact, skepticism on resilience as a theoretical framework for analyzing regional economies is continually raised from a segment of academia. For example, Hassink (2010) is highly critical of resilience on the ground that it means mere adjustment of structures rather than adaptation and renewal, neglecting the evolutionary and adaptive natures of systems change. That is, it does not take history and geography seriously by overlooking the importance of place-specific elements to explain broader spatial patterns of regional industry and technology evolution. ${ }^{3}$ However, by avoiding the equilibrium-centered conception of regional resilience, from which both engineering and ecological resilience heavily draw on their theoretical foundations, and also by introducing the notions of inter-scale interactions (i.e. the revolt and memory linkages), the panarchy framework might be much immune from significant criticisms of resilience.

By incorporating the conception of a dynamical, irreversible, and innovation-driven self-transformational system, the panarchy model opens up high roads to exploring, in the veins of evolutionary adaptive terms, regional economic analysis and development policies. Through a three-step approach, the panarchy model can be operationalized. In the first place, the specific phase at which a regional economy is currently positioned in the relevant adaptive cycle should be identified. Simultaneously, the context-specific critical factors that influence the performance of regional economic resilience, i.e. the resilience facilitators or barriers intrinsic to the identified phase, should also be distinguished.

In the second step, this information is used to suggest the strategic goals and corresponding policy principles to enhance the potential and resilience of regional economies, which are tailored to the idiosyncratic traits (economic, social, institutional, cultural, or technological) of the phase of interest. Here, the policy principles are articulated in terms of activat-

\footnotetext{
${ }^{3}$ Hassink (2010) argues that the concept of resilience in connection with regions might be a useful concept in ecological and disaster studies, but it is much less so in connection to regional economies. He cites three shortcomings of resilience as applied to exploring regional economic systems: (i) the focus on single equilibrium or multi-equilibria; (ii) the neglect of economic agents and functions operating at several spatial scales (e.g. states, institutions, and policies); and (iii) the neglect of cultural and social factors affecting regional economic adaptability.
} 
ing or suppressing various place-specific elements, social relations, knowledge spillovers, or institutional inertia, such as path-dependence or lock-in. If some elements appear to be conducive to boosting regional economic resilience, proactive policies activating them should be promoted and vice versa. The emphasis is here put on the processes and mechanisms that make for or hinder the adaptation of the regional economies, and how spatial and historical contingencies interact with system necessity to determine regional resilience. In addition to the context-specific internal connectedness, the cross-scale linkages and interactions between different scales should be spelled out.

Then, the second step is just a stage of delving into the complex processes of economic adaptation and transformation. More specifically, this means answering the following inquiries: how strongly the regional economy fosters innovations and new firms and industries formation; how the spatial structures of the economy are influenced by the micro-behaviors of economic agents (e.g. individuals, firms, and institutions); how the regional economic landscape exhibits self-organization; and how the processes of path-dependence and path-creation interact to shape geographies of economic development and transformation (Martin and Sunley, 2006; Boschma and Marin 2007). The results of this exploration are expressed by virtue of the various characteristics and factors that shape the patterns of region's reaction to external shocks and disturbances and regional economic resilience (Martin 2012). Such factors include the regional economy's prior growth performance (a strong underlying economic growth dynamic or a weak underlying pre-shock growth dynamic), a region's economic structure (its particular mix of economic activities and the relationships and interdependences between them: a diverse vs. specialized structure), the competitiveness and innovative propensities of its firms, the relational linkages of its firms with networks of other producers and customers in other regions and other countries, the skills of its workforce, its entrepreneurial culture and institutional forms, the stance taken by and the resources and measures available to local policy bodies, and the region's governance arrangements. It is here emphasized that the region's political economic configurations have strong effects on regional economic resilience. Therefore, the region's political economic contours should be explicitly elucidated. They include the patterns of mediation and responses to disturbances on the part of local institutional, cultural, and political conditions; the ways that national policy helps or hinders a region's recovery; and the very na- ture, boundaries, and relational character of regional and local economies as arenas of economic governance and policy activism (Martin 2012).

The third and final step is to specify the strategic goals and policy principles for increasing regional economic resilience. The policy goals and principles should be articulated such that the regional economy can exercise strong resistance to shocks, speedy recovery from a recessionary shock, extensive reorientation entering a new round of adaptation in response to shocks, or renewal of its growth path to prompt a hysteretic shift to new growth trend. On the other hand, the policy principles should be specified in accordance with the social, economic, political, institutional, and cultural characteristics prevailing over the evolutionary phase in the adaptive cycle at which the regional economy is placed. It is argued that achieving and maintaining the learning region is a most focused target of policies influencing regional economic adaptability. Then, given the close conceptual linkage between regional economic adaptability and resilience, a set of policy principles primarily designed to foster formation of the learning region can offer useful reference to specifying polices for the region of interest. Although the following learning region policies are general in scope, they, if adapted to specific contexts and demands for regional policies in the various regions, provide crucial part of adaptation policy (Hassink 2005, 2010):

- Carefully coordinating supply of and demand for skilled individuals

- Developing a framework for improving organizational learning, which is focused not only on high-tech sectors but also on all sectors that have the potential to develop high levels of innovative capacity

- Carefully identifying resources in the region that could impede economic development (lock-ins)

- Positively responding to changes from outside, particularly where this involves unlearning

- Developing mechanisms for coordinating both across departmental and governance (regional, national and supranational) responsibilities

- Developing strategies to foster appropriate forms of social capital and tacit knowledge that are positive to learning and innovation

- Continuously evaluating relationships between participation in individual learning, innovation, and labor market changes

- Fostering redundancy and variety of industries and networks 
- Ensuring the participation of large groups of society in devising and implementing strategies.

So far in this section, detailed is the process of the threestep approach to operationalizing the panarchy model, with the profiles of regional resilience and relevant development policies spelled out. <Table $1>$ presents an example of imaginary simulation for specifying regional policies consistent with the evolutionary adaptive mechanism of regional economies, which could be filled out with proper information obtained from the processes of implementing the panarchy model.

Table 1. Process of implementing the panarchy model and its resultants

\begin{tabular}{|c|c|c|c|c|}
\hline Evolutionary path & Level of dimensions & Economy status & Strategic goal & Promotive policy principles \\
\hline Path I $(\gamma \rightarrow \mathrm{K})$ & $\begin{array}{l}\text { P: Increase } \\
C: \text { Increase } \\
\text { R: Decrease } \\
\text { S: Increase }\end{array}$ & Prosperous/growing & $\begin{array}{l}\text { Reinforce regional } \\
\text { economy's resilience }\end{array}$ & $\begin{array}{l}\text { - Positive lock-ins } \\
\text { - Governance } \\
\text { - Internal linkages } \\
\text { - Spatial boundaries of knowl- } \\
\text { edge }\end{array}$ \\
\hline Path II $(\mathrm{K} \rightarrow \Omega)$ & $\begin{array}{l}\text { P: Decrease } \\
\text { C: Sustained high } \\
\text { R: Decrease } \\
\text { S: Decrease }\end{array}$ & Declining/shrinking & $\begin{array}{l}\text { Increase speed and } \\
\text { degree of recovery }\end{array}$ & $\begin{array}{l}\text { - Delocking-in } \\
\text { - New path-creation } \\
\text { - Inter-scale governance } \\
\text { - External resources } \\
\text { - Heterogeneity of knowledge }\end{array}$ \\
\hline Path III $(\Omega \rightarrow \alpha)$ & $\begin{array}{l}\mathrm{P}: \text { Increase } \\
\mathrm{C}: \text { Decrease } \\
\mathrm{R}: \text { Increase } \\
\text { S: Increase }\end{array}$ & Transitional & $\begin{array}{l}\text { Fasten speed of reori- } \\
\text { entation }\end{array}$ & $\begin{array}{l}\text { - Lock-ins } \\
\text { - Variety of industries } \\
\text { - External linkages } \\
\text { - New thematic focal points } \\
\text { - Path-dependence }\end{array}$ \\
\hline Path IV $(\alpha \rightarrow \gamma)$ & $\begin{array}{l}\text { P: Decrease } \\
\text { C: Sustained low } \\
\text { R: Increase } \\
\text { S: Increase }\end{array}$ & $\begin{array}{l}\text { Transforming/ } \\
\text { restructuring }\end{array}$ & $\begin{array}{l}\text { Renew region's existing } \\
\text { growth path }\end{array}$ & $\begin{array}{l}\text { - New path-creation } \\
\text { - Collaborative governance } \\
\text { - Internal linkages } \\
\text { - Reduced technological } \\
\text { distance }\end{array}$ \\
\hline
\end{tabular}

Note: $\mathrm{P}$ denotes the dimension of potential, $\mathrm{C}$ the dimension of systems connectedness, $\mathrm{R}$ the dimension of regional economic resilience, and $\mathrm{S}$ the intensity of cross-scale interactions.

\section{CONCLUSIONS}

In this paper, attempted is to reconcile the notion of resilience and the prevailing concepts in the disciplines of evolutionary economics and geography. It is proved that panarchy offers a promising outlet within which the seemingly incompatible conceptions can be combined. Taking seriously into consideration the place-specific elements and institutions, it can address why some regions manage to adapt to external shocks, renew themselves, or lock out themselves, while others are more locked in decline. In addition, it can illuminate how the spatial organization of economic production, distribution, and consumption is transformed over time.
Thus, regional economic resilience if combined with panarchy emerges as an alternative framework of explaining regional differentiation in economic performance and trajectories. It is noted, however, that the term is so malleable such that it lacks a clear definition and poses a significant difficulty in operationalization. Consequently, it is likely that the resilience conception is prone to fall into the trap of a fuzzy concept. However, this paper demonstrates that, by using the panarchy model, the elusive concept of regional resilience can be operationalized to illuminate the evolutionary adaptive mechanisms and credible policies adjusted to region-specific social, economic, institutional, cultural, and political contexts. Then, it can be claimed that panarchy, if articulated in the evo- 


\section{Special Contribution}

lutionary adaptation conceptions of regional economies, can provide a useful framework with which both scholars of regional studies and policy-makers attack the intriguing problems of promoting sustained regional economic vitality.

\section{REFERENCES}

Beisner, B. E., Haydon, D. T., and Cuddington, K. (2003) "Alternative stable states in ecology," Frontiers in Ecology and the Environment 1:376-382.

Berks, F., and Folke, C. (1998) "Linking sociological and ecological systems for resilience and sustainability" In Berks, F., and Folke, C., eds. Linking Sociological and Ecological Systems for Resilience and Sustainability: Management Practices and Social Mechanisms for Building Resilience (New York: Cambridge University Press), pp.1-25.

Boschma, R., and Martin, R. (2007) "Editorial: constructing an evolutionary economic geography," Journal of Economic Geography 7: 537-548.

Brenner, N. (2001) "The limits to scale? Methodological reflections on scalar structuration," Progress in Human Geography 25: 691-614.

Bristow, G. (2005) "Everyone's a 'winner': problematizing the discourse of regional competitiveness," Journal of Economic Geography 5: 285-304.

Bristow, G. (2010) "Resilient regions: re-'place'ing regional competitiveness," Cambridge Journal of Regions, Economy and Society 3: 153-167.

Christopherson, S., Michie, J., and Tyler, P. (2010) "Regional resilience: theoretical and empirical perspectives," Cambridge Journal of Regions, Economy and Society 3: 3-10.

Folke, C. (2006) "Resilience: the emergence of a perspective for social-ecological systems analysis," Global Environmental Change 16: 253-267.

Hassink, R. (2005) "How to unlock regional economies from path dependency? From learning region to learning cluster," European Planning Studies 13: 521-535.

Hassink, R. (2010) "Regional resilience: a promising concept to explain differences in regional economic adaptability?," Cambridge Journal of Regions, Economy and Society 3: 45-58.

Holling, C.S. (1973) "Resilience and stability of ecological systems," Annual Review of Ecological Systems 4: 1-23.
Holling, C.S., and Gunderson, L.H. (2002) "Resilience and adaptive cycles," In Gunderson, L.H., and Holling, C.S., eds. Panarchy: Understanding Transformations in Human and Natural Systems (Washington, D.C.: Island Press), pp.52-62.

Jessop, B. (2005) "The political economy of scale and European governance 1," Tijdschrift voor Economische en Sociale Geographie 96: 225-231.

Jessop, B. (2008) "The cultural political economy of the knowledge-based economy and its implications for higher education," In Jessop, B., Fairclough, N., and Wodak, B. eds. Education and the Knorwledge-based Economy in Europe (Rotterdam: Sense Publishers), pp. 11-39.

Krugman, P. (1995) Development, Geography, and Economic Theory (Cambridge, MA: MIT Press).

Lambooy, J.G., and Boschma, R.A. (2001) "Evolutionary economics and regional policy," The Annals of Regional Science 35: 113-131.

MacLeod, G., and Jones, M. (2007) "Territorial, scalar, networked: In what sense a 'regional world'?," Regional Studies 41: 1177-1191.

Martin, R. (2012) "Regional economic resilience, hysteresis and recessionary shocks," Journal of Economic Geography 12: 1-32.

Martin, R., and Sunley, P. (2006) "Path dependence and regional economic evolution," Journal of Economic geography 6: 395-438.

Martin, R., and Sunley, P. (2007) "Complexity thinking and evolutionary economic geography," Journal of Economic Geography 7: 573-601.

McGlade, J., Murray, R., and Baldwin, J. (2006) "Industrial resilience and decline: a co-evolutionary approach," In Garnsey, E. and McGlade, J. eds. Complexity and the Co-evolution: Continuity and Change in Socio-Economic Systems (Cheltenham, England: Edward Elgar), pp. 147-176.

Nelson, D.R., Adger, W.N., and Brown, K. (2007) "Adaptation to environmental change: contributions of a resilience framework," Annual Review of Environment and Resources 32: 395-419.

Pendall, R., Foster, K.A., and Cowell, M. (2010) "Resilience and regions: building understanding of the metaphor," Cambridge Journal of Regions, Economy and Society 3: 71-84.

Pike, A., Dawley, S., and Tomaney, J. (2010) "Resilience, adaptation and adaptability," Cambridge Journal of Regions, 
Economy and Society 3: 59-70.

Pimm, S.L. (1984) "The complexity and stability of eco-systems," Nature 307: 321-326.

Porter, M.E. (2003) "The economic performance of regions," Regional Studies 37: 545-546.

Simmie, J., and Martin, R. (2010) "The economic resilience of regions: towards an evolutionary approach," Cambridge Journal of Regions, Economy and Society 3: 2743.

Swanstrom, T., Chapple, K., and Immergluck, D. (2009) Regional Resilience in the Face of Foreclosures: Evidence from Six Metropolitan Areas. Working Paper, Institute of Governmental Studies, University of California Berkeley. [Online] URL: http://brr.berkeley.edu/author/toddswanstrom/.

Swyngedouw, E. (2004) "Globalization or 'glocalization'? Networks, territories and rescaling," Cambridge Review of International Affairs 17: 25-48.

The Sustainable Project. [Online] URL: http://www.sustainablescale.org/ConceptualFramework/UnderstandingScale/MeasuringScale/Panarchy.aspx.

Toulmin, S. (1981) "Human Adaptation," In Jenson, U.F., and Harre, R., eds. The Philosophy of Evolution (London: Havester Press), pp. 176-195.

Vale, L.J., and Campanella, T.H., eds. (2005) The Resilient City: How Modern Cities Recover from Disaster (New York: Oxford University Press).

Walker, B., Holling, C.S., Carpenter, S.R., and Kinzig, A.P. (2004) "Resilience, adaptability and transformability in social-ecological systems," Ecology and Society 9(2): 5 [online] URL: http://www.ecologyandsociety.org/vol9/ iss $2 / \operatorname{art} 5$.

Yamamoto, D. (2011) "Regional resilience: prospects for regional development research," Geography Compass 5: 723-736. 